\title{
Inclusão digital de idosos: abordagem ergonômica e inteligências múltiplas para elaboração de material didático
}

Márcia Barros de Sales marcia.barros@ufsc.br

André Barros de Sales andrebdes@unb.br

Marília Abrahão Amaral marilia.utfpr@gmail.com

\section{Resumo}

Este artigo apresenta um estudo da participação direta de usuários idosos no processo de elaboração de material didático, utilizando o design centrado no usuário com o intuito de deixá-lo mais atrativo, acessível e didático. Procurou-se alicerçar todas as atividades desse material com as inteligências múltiplas defendidas por Howard Gardner. Para o processo de validação desse material didático, utilizou-se a técnica empírica de oficinas de interação, que exige a participação direta dos envolvidos. Assim, foi realizada uma avaliação qualitativa desses materiais pelos usuários, cujos resultados são aqui apresentados. Participaram deste estudo 31 idosos, com média de idade de 65 anos e com grau de escolaridade heterogênea, frequentadores do projeto de extensão "Oficinas de Informática para a Terceira Idade", da Universidade Federal de Santa Catarina.

Palavras-chave: Inclusão digital de idosos. Abordagem ergonômica. Inteligências múltiplas. Material didático.

\section{Digital inclusion of the elderly: multiple intelligen- ces and ergonomic approach for teaching material development}

\begin{abstract}
This paper presents the study of elderly users direct participation in the preparation of teaching material using user-centered design in order to make it more attractive, accessible and educational. We sought to underpin all its activities through multiple intelligences defended by Howard Gardner. For the teaching material validation process we used the empirical technique of interactive workshops that requires direct
\end{abstract}


participation of those involved. In this manner, a qualitative assessment of these materials by users was performed, which results are presented here. The study included 31 elderly users, with a mean age of 65 years and heterogeneous schooling, participants of the extension project of "Computer Workshops for The Elderly" the Federal University of Santa Catarina.

Key words: Digital inclusion of the elderly. Ergonomic approach. Multiple Intelligences. Courseware.

\section{INTRODUÇÃO}

O envelhecimento traz consigo diferentes demandas de atenção à pessoa idosa, como a necessidade de mantê-la ativa e participante.

Nos dias atuais, os idosos necessitam de acesso ao mundo da informática e ser incluídos digitalmente. Para isso, é necessário buscar alternativas inclusivas e acessíveis que viabilizem a interação do idoso nesse novo domínio virtual, oferecendo-lhe ferramentas de comunicação e informação dos dispositivos digitais. Tais alternativas devem considerar algumas barreiras, como a linguística e a baixa alfabetização de grande parte desse público (IBGE 2012), que podem atrapalhar ou impedir sua interação com essas ferramentas. Por exemplo: conteúdos didáticos não adaptados ao contexto dos idosos (por não dominarem estrangeirismos como deletar, on-line, plugar, resetar etc.) podem dificultar sua interação com o computador.

No Estatuto do Idoso, Lei n. 10.741/2003, no Capítulo V, lhe é assegurado o direito “[...] à educação, cultura, esporte, lazer, diversões, espetáculos, produtos e serviços que respeitem sua peculiar condição de idade." Dispõe o art. 21: "O poder público criará oportunidades de acesso do idoso à educação, adequando currículos, metodologias e material didático aos programas educacionais a ele destinados.” (BRASIL, 2003).

Somado a essas considerações, é necessário mapear estratégias de ensino orientadoras e facilitadoras para a aprendizagem do idoso que considerem sua história de vida, linguagem e alterações cognitivas, emocionais e físicas.

A proposta é apresentar as etapas de desenvolvimento de um protótipo de material didático com conteúdos de informática básica para idosos. A preocupação maior, porém, é oportunizar ao idoso não só as informações sobre o computador e suas ferramentas de comunicação e informação, mas disponibilizar-lhe recursos que facilitem a compreensão dessas novas informações recebidas durante o aprendizado.

Para alcançar os propósitos deste artigo, na primeira seção, busca-se fornecer uma revisão sobre a abordagem ergonômica, definições de design centrado no usuário e acessibilidade adotadas neste estudo. $\mathrm{Na}$ seção seguinte, abordam-se alguns referenciais teóricos sobre inteligências múltiplas. Em seguida, descrevem-se os passos metodológicos utilizados para o desenvolvimento do material didático realizado em 2010. Prosseguindo, relata-se a metodologia empregada para desenvolver o material didático com conteúdo de informática. Posteriormente, passa-se à apresentação dos resultados obtidos e sua discussão. Por fim, na última seção, tecem-se algumas considerações sobre a importância da inclusão digital da população idosa.

\section{Referências Ergonômicas: Design Centado no Usuário, Acessibilidade}

No estudo relatado no artigo "Introducing human-centered research to game design: designing game concepts for and with senior citizens", Abeele e Van Rompaey (2006) apresentam uma metodologia centrada no humano para inovar jogos, baseada em princípios etnográficos e design participativo. Essa metodologia foi aplicada num projeto para desenvolver conceitos de jogos para idosos em seu "habitat natural", pesqui- 


\section{Extensio $\mid$ Artigo}

sando quais experiências positivas ocorriam em sua vida diária.

Questões levantadas nas investigações de Sayago et al. (2007), Sales e Cybis (2002), Raabe et al. (2005) e Abeele e Van Rompaey (2006) relatam a importância de promover atividades participativas com idosos para construir e avaliar interfaces, informatizadas ou não, mais acessíveis e usáveis e, acima de tudo, que respeitem suas limitações, experiências de vida e desejos.

A utilização de Design Centrado no Usuário (DCU), técnica de Interface Humano Computador (IHC), foi abordada em Sales e Fialho (2007a) e, além disso, essa mesma referência contempla reflexões sobre as abordagens gerontológicas, educacionais, ergonômicas e iniciativas de inclusão digital mais adequadas para os idosos.

Percebe-se que o relacionamento humano-computador se traduz num processo constante de flexibilidade e adaptação. É importante ressaltar que as pessoas possuem diferentes tipos de habilidades, o que reforça a importância do envolvimento dos usuários-finais para desenvolver projetos como o aqui apresentado.

O envolvimento participatório é muito importante para a autoestima do usuário e pode ser determinante para o sucesso da interface. Nesse sentido, Cybis (2006) cita que a equipe de projeto que adota um enfoque centrado no usuário deve ter em mente os três tipos básicos de envolvimento possíveis: informativo, quando o usuário é visto como fonte de informação; consultivo, quando o usuário é consultado para verificar e emitir informações e opiniões sobre as decisões do projeto; e participatório, estágio mais elevado de envolvimento, com a transferência de poder decisório para o usuário, na validação e na exploração das características da futura interface.

Para Muller et al. (1997), a participação ativa do usuário transcende sua simples utilização como fonte de dados, submetendo-o a questionários ou observando como ele utiliza um programa ou realiza uma tarefa. Acredita-se que, num projeto participatório, deve-se ter uma noção global do processo de vida do idoso, contextualizando-o por sua realidade individual, social, cultural e histórica.

Essa visão se coaduna com a apresentada por Medina (2007), segundo a qual, nas etapas do design centrado no usuário, é necessário conhecer a realidade do futuro "operador", ou usuário do produto, levando em conta idade, nível cultural, escolaridade, limitações físicas e capacidades.

Neste trabalho, adota-se a definição de acessibilidade utilizada pela Organização das Nações Unidas (ONU), segundo a qual a acessibilidade é o processo de conseguir a igualdade de oportunidades em todas as esferas da sociedade.

\subsection{Cognição, percepção, interação humano-computador e idosos}

Entre os objetivos da ergonomia cognitiva, identifica-se o de tornar as tarefas mais fáceis, efetivas e prazerosas em sua execução e seguras para os usuários. Ao realizarem uma aproximação ergonômica com sistemas informatizados, Cañas e Waerns (2001) concluíram que, quando se fala da interação humano-computador, pode-se analisar a conduta interativa em diferentes níveis. Os autores associaram alguns artefatos informatizados a temas relacionados aos fatores humanos (interesse) e os classificaram em quatro níveis. São eles:

O primeiro deles é o sociocultural.

-Os temas de interesse relacionados com o papel da tecnologia da informação na organização da sociedade, história, cultura: trabalho a distância, comunidades virtuais.

-Os artefatos informáticos são: e-mail, e-conferências.

O segundo nível é o da cooperação.

-Os temas de interesses relacionados com a comunicação e coordenação.

-Artefatos informáticos, como: cscw, wiki, em que várias pessoas cooperam. 
O terceiro é o da percepção individual.

-Os temas de interesses relacionados com a representação, interpretação.

-Os artefatos informáticos são: sistemas de apresentação de dados visuais, sonoros, táteis e sistemas de saída e manipulação de dados.

O quarto é o do feedback (retorno).

-Os temas de interesse são: os desenhos de instrumentos de entrada relacionados com as saídas (problemas físicos, interação com o mundo real).

-Artefatos informáticos são: interação motora e realidade virtual.

A percepção é um processo cognitivo de interpretação ou análise mental da informação. Para processar a informação, o sistema cognitivo utiliza uma série de recursos simultaneamente e, dependendo da complexidade da tarefa ou do nível de aprendizagem ou experiência prévia, o sujeito poderá utilizá-la com eficácia ou se produzirá um excesso de carga mental que gerará deficiências na execução (CAÑAS; WAERNS, 2001).

Em suas pesquisas sobre cognição, envelhecimento e interação de idosos com o computador, Xavier (2002) enfatiza que há quatro níveis de recursão do sistema cognitivo. Esses níveis foram alicerçados na visão da biologia do conhecimento em Maturana e Varela (1980), nas qualidades ergonômicas para a Interação Humano-Computador (IHC) e relacionam-se com o uso de algumas ferramentas disponíveis no computador e na internet. Segundo Xavier (2002), o uso dessas ferramentas pode ajudar o idoso a desenvolver sua capacidade lógico-formal para cada nível de interação (recursão). Cada nível de evolução (recursão) corresponde a uma estrutura de discurso própria e a um nível de complexidade, como demonstrado a seguir:

Nível 1: "Desenvolvimento psicomotor"1 - contato direto com o computador, aproximação, aparece o movimento. Mouse, teclados, teclado virtual, MS Paint, galerias de fotografias, apresentações em Power Point etc.

Nível 2: "Identidade" - diante da interação com o computador e as ferramentas de informação e comunicação disponibilizadas na internet, surge uma nova identidade, o "usuário". Navegação na internet, jogos individuais.

Nível 3: "Autoconsciência" - emergem o compromisso e a consciência crítica, estabelecendo caminhos e responsabilidades. Máquina de busca (Google, Yahoo etc.), blogs, jogos de perguntas e respostas, jogos de realidade virtual.

Nível 4: "Alteridade" - emergência do outro (troca e cooperação), que pode ser percebida no discurso pelo aparecimento do "nós". Chat, vídeo-conferência, redes sociais, jogos cooperativos, correio eletrônico, listas de discussão.

Esses níveis podem ser alcançados à medida que vai mudando de nível, aumenta a complexidade da tarefa a ser realizada. O autor defende ainda que cada nível de complexidade supracitado corresponde a um ganho qualitativo no qual o sistema cognitivo opera com maior capacidade.

Sales e Cybis (2002) levantam algumas questões da influência do envelhecimento e algumas alterações funcionais decorrentes da idade e suas possíveis implicações durante a interação do idoso com o computador. São elas: alterações cognitivas, que podem influenciar a concentração, memorização, leitura ou percepção; dependem do ambiente de estresse, de doenças (Alzheimer), de uso de remédios, de fatores genéticos; da diminuição da capacidade de manter a atenção (principalmente em situações divididas); da redução da capacidade da memória de trabalho (principalmente a visual); diminuição da capacidade de tratar a informação (lógica e aprendizado); redução da capacidade de compreensão do discurso; e alterações

1 Movimento coordenado no espaço e no tempo. 


\section{Extensio $\mid$ Artigo}

emocionais: declínio na autoestima, apatia, desmotivação; falta de iniciativa (esperando e acatando ordens), pouca exploração do meio, pouca iniciativa, depressão, tristeza, irritabilidade, isolamento social decorrente principalmente da diminuição das atividades diárias (inatividade), preocupação com dinheiro, saúde, segurança; defasagem ou exclusão tecnológica.

Essas alterações podem dificultar a interação dos idosos com computador quando lhes forem solicitadas tarefas com tempo definido, tais como: ler e compreender as informações em tela cheia de dados, perceber a função de um objeto (interpretar qual é a função de um ícone, por exemplo) a lidar com erros e incidentes.

Diante do exposto e da necessidade de incentivo à educação permanente para idoso, o objetivo deste artigo é apresentar alguns resultados de uma pesquisa sobre o desenvolvimento de material didático com conteúdos de informática, procurou-se alicerçar cada atividade do material didático na proposta de Nogueira (2001) no que se refere aos estímulos das inteligências múltiplas e aos quatro níveis de recursão (XAVIER, 2002) quando da interação do idoso com as ferramentas da informática.

\section{ESTÍMULO DAS INTELIGÊNCIAS MÚLTIPLAS}

Para Gardner (1999), todas as pessoas são dotadas de várias inteligências: a diferença está em como cada indivíduo as estimula para bem desenvolvê-las.

"É incontestável o fascínio que o computador exerce sobre os alunos, independente da sua idade. Talvez o fato se dê pela possibilidade da interação que ele representa [...]" (NOGUEIRA, 2001). O autor comenta ainda que é possível estimular as inteligências múltiplas do aprendiz durante a sua interação com as ferramentas informatizadas, a saber:

Inteligência lógico-matemática: palavras cruzadas, e-mail com exercícios de raciocínio, jogos lógicos, jogos lúdicos, resolução de problemas, etc.

Inteligência espacial: softwares que trabalhem com desenhos, imagens, fotografias (Paint, Powerpoint, Photoshop), navegação na Web (hipertextos, hipermídia, links) e controlar várias janelas na área de desktop etc.

Inteligência linguística: softwares de editoração de texto, e-mail, chat, elaboração de apresentações, palavras cruzadas etc.

Inteligência musical: sites de rádio, vídeos e apresentações recebidas por e-mail, etc.

Inteligência corporal-sinestésica: habilidade no manuseio do mouse, em softwares que trabalham com desenhos, fotografias, imagens etc.

Inteligência interpessoal: receber um e-mail com mensagens de motivação, otimismo, utilizar o bate-papo/chat.

Inteligência emocional: receber/enviar um e-mail ou uma mensagem via chat.

No entendimento de Nogueira (2001), o importante durante a construção do projeto é que o caminho percorrido funcione igual a um fio condutor entre as etapas de elaboração e a aprendizagem, que se vai consolidando conforme o contexto experimentado ao longo de sua elaboração.

Esta pesquisa preocupa-se em oportunizar não só as informações sobre o computador e suas ferramentas de comunicação e informação, mas também recursos que facilitem para o idoso a compreensão dessas novas informações adquiridas durante o seu aprendizado. Para isso, primou-se por elaborar os conteúdos do material didático, a fim de estimular e explorar as inteligências múltiplas durante a interação do idoso e as ferramentas de comunicação disponibilizadas na internet, conforme Nogueira (2001). 


\section{METODOLOGIA}

Quanto à metodologia, esta pesquisa está baseada principalmente nas orientações procedimentais da pesquisa-ação, método que reúne diversas técnicas de pesquisa social com as quais se estabelece uma estrutura coletiva, participativa e ativa na captação da informação, requerendo, portanto, a participação das pessoas envolvidas no problema investigado (THIOLLENT, 1998). O método de análise de dados foi qualitativo, com uso de questionários e a participação do usuário idoso em oficinas. Essa metodologia converge com a abordagem ergonômica adotada nesta pesquisa, que envolve o usuário em todo o processo de concepção de projetos ou produtos aqui já relatados.

Neste estudo, adotou-se a abordagem ergonômica ${ }^{2}$ para as atividades de desenvolvimento e avaliação dos materiais didáticos quando do seu uso e apropriação pelos idosos durante as oficinas de informática. Para isso, utilizou-se a técnica empírica denominada oficinas de interação ${ }^{3}$, escolhida por exigir a participação direta dos usuários em interações reais ou simuladas, nas quais se observa a realização de um conjunto de tarefas específicas.

A adoção da abordagem ergonômica como técnica de avaliação pode proporcionar maior aproximação do pesquisador com seu público-alvo, convergindo para atividades do design centrado no usuário, que são: envolver o usuário em todas as etapas do processo de desenvolvimento do projeto ou produto; conhecer o usuário; identificar suas necessidades e preferências; observar a interação do usuário com o produto e seu rendimento em determinada tarefa; questioná-lo sobre quais tarefas devem ser realizadas e quais as ideias e soluções para as tarefas (ISO 13407; MEDINA, 2007).

Entre as ferramentas para avaliar as inteligências múltiplas (Gardner) encontra-se o inventário das inteligências múltiplas criado por Armstrong em 2001, instrumento composto por um questionário com perguntas fechadas utilizado na comunidade acadêmica. Com o intuito de fazer com que os idosos participassem da avaliação do material didático e pudessem opinar sobre qual inteligência estava sendo estimulada no material didático e na interação com o computador, adotou-se o uso de oficinas de interação para coletar in loco a opinião dos idosos participantes.

A equipe técnica que acompanhou as oficinas de interação foi composta por uma ergonomista e um bolsista. Para registrar problemas e dificuldades relatados pelos idosos durante as oficinas ou observados pela equipe técnica, foram utilizados: câmera filmadora, anotações manuais e digitais e questionários com perguntas abertas e fechadas. O uso desses instrumentos teve a anuência dos participantes formalizada com o Termo de Consentimento Livre e Esclarecido devidamente assinado, conforme Resolução n. 196/CNS.

\section{CONTEXTO DA PESQUISA}

Nos últimos anos, o Núcleo de Estudos da Terceira Idade da Universidade Federal de Santa Catarina (NETI/UFSC) registrou aproximadamente 100 idosos interessados em aprender informática e internet. Alguns idosos que frequentaram curso de informática sem vínculo com o NETI queixavam-se do ritmo e da heterogeneidade da turma, que variava do jovem ao idoso. Reclamavam também dos materiais didáticos, que, em sua maioria, lhes eram inadequados (SALES, 2007a).

Consequentemente, alguns deles não conseguiam acompanhar o grupo no qual estavam inseridos, tornando a situação constrangedora e levando-os a abandonar as aulas.

2 Um dos princípios básicos da abordagem ergonômica é conhecer para modificar uma realidade de trabalho, sejam eles informatizados ou não. Isso implica uma análise das situações reais como meio de identificar as necessidades dos usuários. Essa análise pode ser feita por meio de entrevistas e observações.

3 Oficina como técnica de observação da interação, que se diferencia dos ensaios de interação pela informalidade e pelo número de usuários participantes. No ensaio de interação, pode participar apenas um usuário; enquanto em oficina, podem participar vários usuários. 
Tendo em vista essa dificuldade, em março de 2003, iniciou-se, com o apoio do NETI, o projeto intitulado "Oficinas de internet para terceira idade", situado no Laboratório de Sistemas de Conhecimento (LSC) do Departamento de Informática e Estatística (INE) da Universidade Federal de Santa Catarina. Em 2011, as oficinas passaram a ser realizadas no laboratório de informática no NETI.

Entre as razões apontadas, destacou-se que o material didático utilizado continha textos longos com muitas informações e poucas ilustrações, letras pequenas, palavras no idioma inglês sem tradução e poucos recursos de orientação, como, por exemplo, ilustrações sobre determinada tarefa ou ação que estava sendo ensinada ou requisitada. $\mathrm{O}$ resultado, consequentemente, foi que alguns idosos se sentiam inseguros em muitas tarefas e não recorriam ao material didático por achá-los de difícil compreensão.

Nesse contexto, é necessário aprimorar o desenvolvimento de materiais didáticos para as pessoas idosas, fomentando o uso de abordagens pedagógicas, estratégias de ensino e recursos didáticos condizentes com as características do adulto idoso, diferentemente das que são utilizadas para crianças, jovens e adultos. Essa falta de cuidado na elaboração/desenvolvimento de recursos didáticos pode influenciar negativamente no interesse do aprendiz idoso, dando-lhe a impressão de que o tema é complexo e difícil, a ponto de fazêlos desanimar e acabar deixando o curso.

\subsection{Aplicação da pesquisa: reelaborar e atualizar o material didático para idosos}

A partir dessas oficinas e com base nas observações iniciadas em 2003, partiu-se para a elaboração da primeira versão do material didático, relatada em Sales et al. (2007b). Este material didático foi base para o primeiro livro de Informática para Terceira Idade disponibilizado na Biblioteca Nacional sobre o tema (SALES, 2007c).

Depois de três anos, esse material didático precisou ser revisado e atualizado. Essa nova versão do material obedeceu às recomendações ergonômicas, às abordagens pedagógicas e às estratégias de ensino que se adequassem ao contexto dessa população, principalmente considerando as transformações funcionais decorrentes da idade mencionadas em Sales e Fialho (2007a). Com o propósito de facilitar a aprendizagem e de tornar o conteúdo e o uso do material didático acessível e também de melhorar a inteligibilidade do material didático pelos idosos, foi dada uma atenção especial à formatação de todos os textos, adequando cores, tipo de fonte, tamanho da fonte, imagens, figuras e sinalizações desse material didático. Cada atividade é um passo a passo com várias oficinas propostas, como:

Atividade 1 - Descobrindo o computador. Esta atividade tem a finalidade de apresentar alguns componentes e dispositivos básicos do computador.

Atividade 2 - Desenhando (trabalhando a motricidade). Esta atividade auxilia o idoso a trabalhar a psicomotricidade no manuseio do mouse e o orienta a olhar o cursor na tela enquanto ele movimenta o mouse sobre a mesa.

Atividade 3 - Editando e formatando texto. Esta atividade fornece um passo a passo para digitar um texto e fazer formatações básicas, tais como: alterar tamanho, tipo e cor da fonte, formatar e alinhar parágrafo, inserir figura.

Atividade 4 - Internet: consultando e pesquisando. Nesta atividade, o idoso-aprendiz navega pela internet.

Atividade 5 - Projeto Integrador I. Esta atividade busca unir todo o conteúdo das atividades anteriores. Para isso, o aprendiz monta o seu primeiro projeto utilizando as ferramentas e os conhecimentos adquiridos durante as oficinas das atividades 2, 3 e 4 do material didático (estratégia de ensino por projetos).

Atividade 6 - E-mail/correio eletrônico. Esta atividade aborda as principais ações para abrir, consultar, encaminhar, compor, excluir e enviar e-mail.

Atividade 7 - Conversando na internet. Esta atividade fornece um passo a passo para utilizar um programa de mensagens instantâneas/bate-papo. 
Atividade 8 - Projeto integrador II. Nesta atividade, o aprendiz elabora um projeto de tema livre, ou seja, um tema sobre o qual ele tenha curiosidade/interesse em estudar. Para concluir o projeto, o aluno deve recordar as atividades 2, 3 e 4 do material didático (estratégia de ensino por projetos) para realizar o projeto. Finalizado o projeto, o aprendiz deve enviá-lo (e-mail) para seus professores e colegas de grupo, com o intuito de compartilhar seu trabalho.

Além do propósito de reelaborar e atualizar o material didático que facilitasse o aprendizado de conteúdos sobre informática básica pelos idosos, primou-se por elaborar atividades que fossem capazes de envolver o aprendiz e estimular suas inteligências múltiplas, durante a sua interação com o computador e suas ferramentas, citado anteriormente por Nogueira (2001)

O mesmo cuidado foi tomado para realizar o equivalente com os níveis de interação (recursão) criados por Xavier (2002). A intenção foi que as atividades do material pudessem incitar a capacidade lógico-formal dos idosos durante o seu uso, como demonstrado no Quadro 1.

\begin{tabular}{|c|c|c|}
\hline Material Didático & Inteligências Múltiplas & Níveis de Interação (Recursão) \\
\hline $\begin{array}{l}\text { Atividade } 1 \text { - Descobrin- } \\
\text { do o computador }\end{array}$ & $\begin{array}{l}\text { Inteligência espacial e } \\
\text { corporal-sinestésica }\end{array}$ & $\begin{array}{l}\text { Nível } 1 \text { - Desenvolvimento psicomo- } \\
\text { tor } \\
\text { Nível } 2 \text { - Identidade }\end{array}$ \\
\hline $\begin{array}{l}\text { Atividade } 2 \text { - Desenhan- } \\
\text { do }\end{array}$ & $\begin{array}{l}\text { Inteligência espacial e } \\
\text { corporal-sinestésica }\end{array}$ & $\begin{array}{l}\text { Nível } 1 \text { - Desenvolvimento psicomo- } \\
\text { tor }\end{array}$ \\
\hline $\begin{array}{l}\text { Atividade } 3 \text { - Editando e } \\
\text { formatando texto }\end{array}$ & $\begin{array}{l}\text { Inteligência linguísti- } \\
\text { ca, espacial e lógico- } \\
\text { matemática }\end{array}$ & $\begin{array}{l}\text { Nível } 1 \text { - Desenvolvimento psicomo- } \\
\text { tor }\end{array}$ \\
\hline $\begin{array}{l}\text { Atividade } 4 \text { - Internet: } \\
\text { consultando e pesqui- } \\
\text { sando }\end{array}$ & $\begin{array}{l}\text { Inteligência espacial, ló- } \\
\text { gico-matemática e mu- } \\
\text { sical }\end{array}$ & $\begin{array}{l}\text { Nível } 1 \text { - Desenvolvimento psicomo- } \\
\text { tor } \\
\text { Nível } 2 \text { - Identidade } \\
\text { Nível } 3 \text { - Autoconsciência }\end{array}$ \\
\hline $\begin{array}{l}\text { Atividade } 5 \text { - Projeto de } \\
\text { Integrador I }\end{array}$ & $\begin{array}{l}\text { Inteligência linguísti- } \\
\text { ca, espacial, corporal- } \\
\text { sinestésica e lógico- } \\
\text { matemática }\end{array}$ & $\begin{array}{l}\text { Nível } 1 \text { - Desenvolvimento psicomo- } \\
\text { tor } \\
\text { Nível } 2 \text { - Identidade } \\
\text { Nível } 3 \text { - Autoconsciência }\end{array}$ \\
\hline $\begin{array}{l}\text { Atividade } 6 \text { - Correio ele- } \\
\text { trônico }\end{array}$ & $\begin{array}{l}\text { Inteligência linguística, } \\
\text { interpessoal, espacial, } \\
\text { emocional, musical e ló- } \\
\text { gico-matemática }\end{array}$ & $\begin{array}{l}\text { Nível } 1 \text { - Desenvolvimento psicomo- } \\
\text { tor } \\
\text { Nível } 2 \text { - Identidade } \\
\text { Nível } 3 \text { - Autoconsciência } \\
\text { Nível } 4 \text { - Alteridade }\end{array}$ \\
\hline $\begin{array}{l}\text { Atividade } 7 \text { - Conversan- } \\
\text { do na internet }\end{array}$ & $\begin{array}{l}\text { Inteligência interpes- } \\
\text { soal, linguística, espa- } \\
\text { cial e emocional }\end{array}$ & $\begin{array}{l}\text { Nível } 1 \text { - Desenvolvimento psicomo- } \\
\text { tor } \\
\text { Nível } 2 \text { - Identidade } \\
\text { Nível } 3 \text { - Autoconsciência } \\
\text { Nível } 4 \text { - Alteridade }\end{array}$ \\
\hline
\end{tabular}




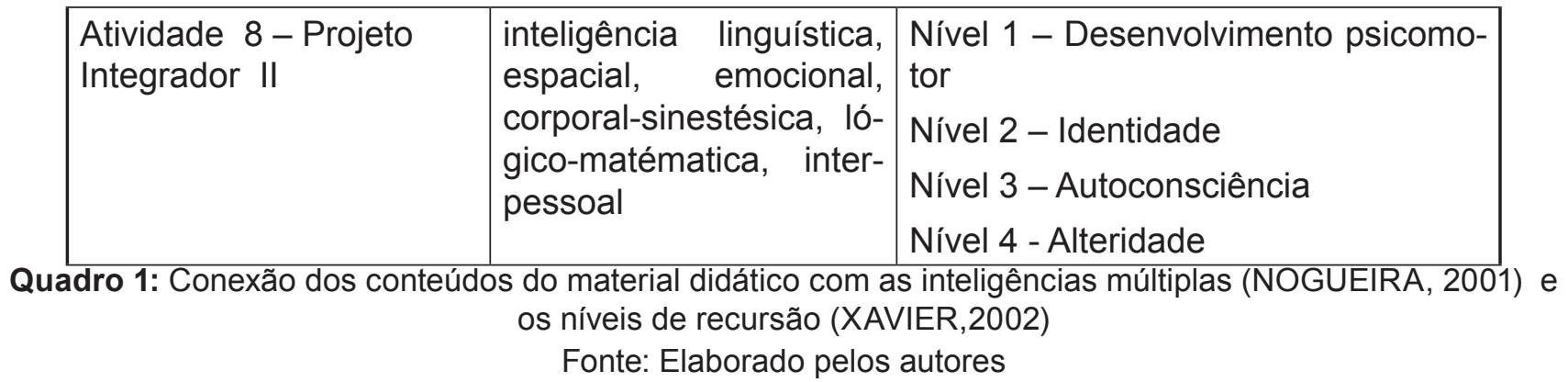

Para pôr em prática a utilização da técnica do DCU para idosos e elaborar o material didático, em meados de 2010, foram convidados dez idosos frequentadores das oficinas de informática (quatro homens e seis mulheres), com grau de escolaridade heterogêneo (ensino fundamental completo a superior completo), todos com mais de 60 anos, que colaboraram voluntariamente nas oficinas para avaliar os conteúdos já existentes no material e sugerir inclusão e/ou exclusão de conteúdos para o material didático.

Depois de se realizarem as modificações no material didático sugeridas pelos idosos nessas oficinas e com o intuito de verificar a inteligibilidade, acessibilidade e o estímulo das inteligências múltiplas deste material, foram realizadas novas oficinas de avaliação no final de 2010 com outros 31 participantes, com média de idade de 65 anos. O Quadro 2 mostra a diversidade de idade e de escolaridade desses participantes.

\begin{tabular}{|c|c|c|c|c|c|c|}
\hline & \multirow[b]{2}{*}{$\begin{array}{l}\text { Faixa } \\
\text { etária }\end{array}$} & \multirow{2}{*}{$\begin{array}{l}\text { N. de } \\
\text { i d o - } \\
\text { sos }\end{array}$} & \multicolumn{4}{|c|}{ Nível de escolaridade } \\
\hline & & & Básico & Fundamental & Médio & $\begin{array}{l}\text { Sup e - } \\
\text { rior }\end{array}$ \\
\hline \multirow{4}{*}{2010} & $A$ & 5 & $0 \%$ & $20 \%$ & $40 \%$ & $40 \%$ \\
\hline & B & 12 & $0 \%$ & $17 \%$ & $42 \%$ & $42 \%$ \\
\hline & $\mathrm{C}$ & 8 & $13 \%$ & $0 \%$ & $50 \%$ & $38 \%$ \\
\hline & $\mathrm{D}$ & 6 & $0 \%$ & $33 \%$ & $33 \%$ & $33 \%$ \\
\hline
\end{tabular}

Esses participantes foram divididos em duas turmas: uma com 15 e outra com 16 alunos. Cada turma teve uma oficina de três horas para avaliar material didático que eles tinham acabado de utilizar durante as oficinas em 2010. As oficinas de interação tiveram a intenção de ajustar o material didático para torná-lo mais acessível e inteligível aos idosos e verificar, por meio de questionários e entrevistas, se eles concordavam com o(s) estímulo(s) associado(s) à(s) atividade(s) durante seu uso.

A dinâmica iniciou-se com a leitura do enunciado de cada atividade; e, na sequência, os usuários deviam responder objetivamente a um questionário avaliando cada atividade do material. Todas as queixas e (ou) dificuldades relatadas foram anotadas pela equipe de avaliação para análise e, em caso de pertinência, para orientar eventuais modificações no material didático.

As duas turmas receberam explicações claras e concisas sobre definições, com exemplos, de inteligências múltiplas, para que, durante a oficina, eles pudessem interagir por meio de questionário e entrevista com a equipe técnica e opinar sobre os estímulos que eles perceberam em cada atividade trabalhada durante as oficinas.

Nessas oficinas, os usuários idosos foram as fontes de informações, foram consultados, emitiram opiniões, exploraram e decidiram como deveria ficar cada conteúdo, abrangendo os três tipos de envolvimento do usuário citados por Cybs (2006): informativo, consultivo e participatório. Na próxima seção, são apresentados os resultados deste estudo. 


\section{RESULTADOS E DISCUSSÕES}

Foi feita uma explicação concisa sobre as inteligências múltiplas e demonstrados alguns exemplos, com a intenção de apresentar aos idosos a relação de cada atividade do material didático com as inteligências múltiplas. Das anotações feitas pelos idosos e pela equipe técnica durante as oficinas, eis alguns resultados:

Atividade 1 - Descobrindo o computador. Os alunos deveriam identificar parte do computador e seus componentes. As inteligências aqui estimuladas foram: a espacial e corporal-sinestésica, já que os alunos tinham a seu dispor um gabinente de computador desmontado e alguns dispositivos de entrada, saída e armazenamento do computador sobre uma mesa que lhes exigiram locomoção para ver as peças e manuseá-las sem pressa, aproximando-os do computador com o intuito de reduzir o "medo" que alguns idosos relataram. Observou-se, na atividade 1, que todos os idosos demonstraram muita curiosidade para saber o que tinha dentro do gabinete.

Atividade 2 - Desenhando. Tinha como finalidade trabalhar a motricidade e a coordenação com mouse. Aqui, $100 \%$ dos idosos concordaram que as inteligências espacial e corporal-sinestésica foram as mais aguçadas; mas foram unânimes em admitir as dificuldades em localizar o ponteiro do mouse e de associar seu movimento com o mouse na tela do computador. Nesta atividade, foi notada uma grande dificuldade no manuseio do mouse pelos idosos, em virtude da destreza reduzida pelas limitações físicas (artrose, artrite).

Atividade 3 - Editando e formatando texto. Forneceram-se alguns recursos básicos de formatação de texto. As inteligências aqui estimuladas foram a linguística, espacial e lógico-matemática. Os idosos revelaram dificuldade com o teclado, queixa mais frequente principalmente dos que tinham baixa escolaridade e limitações físicas (artrose, artrite); foi a atividade mais demorada para completar. Neste caso, 100\% dos idosos concordaram que houve estímulo da inteligência linguística e espacial. Cerca de $70 \%$ dos idosos disseram que a inteligência lógico-matemática também foi estimulada, referindo-se à formatação de texto.

Atividade 4 - Internet consultando e pesquisando. Esta é uma das preferidas dos idosos. Nota-se, porém, alguma confusão no acesso de várias páginas: eles se perdem com muita facilidade, sobretudo quando acessam vários links. Todos os alunos foram unânimes em ressaltar que a inteligência espacial é a mais estimulada, embora $40 \%$ dos idosos tenham enfatizado que a inteligência lógico-matemática e linguística também é muito utilizada nesta atividade.

Atividade 5 - Projeto Integrador I. O objetivo principal desta atividade foi unir todo o conteúdo das atividades. $100 \%$ dos idosos concordaram que houve estímulo das inteligências linguística, corporalsinestésica e lógico-matemática, e cerca de $80 \%$ deles também citaram o estímulo da inteligência espacial.

Atividade 6 - Correio eletrônico. Outra atividade preferida dos idosos. Eles concordaram em 100\% no uso da inteligência interpessoal, linguística, espacial, emocional, lógico-matématica e musical; 30\% dos idosos discordaram sobre a inteligência corporal-sinestésica. Para os idosos que tinham baixa escolaridade, percebeu-se uma maior dificuldade/resistência nas ações de compor ou responder $e$-mail.

Atividade 7 - Conversando na internet. Os idosos utilizaram MSN e o Skype, exercitando inteligência interpessoal, linguística, espacial e emocional. Todos concordaram sobre o estímulo dessas inteligências; porém, 70\% deram ênfase à inteligência espacial, visto que eles tiveram dificuldade em gerenciar mais de uma janela de bate-papo, o que dificultou sua comunicação. Percebeu-se que os idosos que tinham baixa escolaridade se sentiram mais à vontade e confiantes, visto que notaram que se faziam entender mesmo digitando palavras ou frases erradas.

Atividade 8 - Projeto Integrador II. Esta atividade foi a menos apreciada pelos idosos, por exigir a união de todos os conhecimentos apreendidos nas oficinas, e a maioria dos idosos, cerca de $60 \%$, achou esta atividade muito difícil. As inteligências aqui estimuladas foram: inteligência interpessoal, linguística, espacial, corporal-sinestésica, emocional e lógico-matématica. Dos idosos que realizaram esta atividade, $60 \%$ concordaram com todos os estímulos citados. 
A seguir, apresentam-se os depoimentos coletados por meio de entrevista e observações realizadas pela equipe técnica do projeto, com os níveis de escolaridade variando entre $4^{\mathrm{a}}$ série do ensino fundamental e ensino superior.

"O material didático ajuda a gente reforçar o que a gente aprende nas oficinas"; "Foi muito bom porque consegui pegar na internet uma imagem e um texto e colocar junto com o meu texto que eu digitei no editor"; "Eu aprendi muita coisa porque aprendi fazendo, o passo a passo foi muito importante, pois o que eu fazia na oficina eu conseguia fazer em casa sem dificuldade"; "Foi ótimo, consegui aprender a lidar com o computador e isso foi muito importante pra mim"; "Achei difícil no começo, tinha medo de errar, depois me esforcei, mas eu consegui terminar"; "É muito importante fazer os projetos porque mostra tudo o que o aluno aprendeu até agora"; "O passo a passo do material me ajudou muito. Quando imprimi o meu projeto, percebi o tanto que já havia aprendido".

É importante ressaltar que, nas anotações, depoimentos e nas observações da equipe técnica dos vários grupos que frequentaram e frequentam as oficinas de inclusão digital, é recorrente o discurso verbal do "medo de errar" (estragar, sumir ou deletar algo) na interação com o computador e suas ferramentas de informação e comunicação. Percebe-se que isso é inerente à pessoa idosa, o que a impede, na grande maioria da vezes, de avançar, ousar e até mesmo de fazer novas descobertas, sem ajuda de terceiros; daí a importância de materiais didáticos focados para esse público que atendam às demandas decorrentes da idade e que sejam acessíveis, inteligíveis e atrativos.

\section{CONSIDERAÇÕES FINAIS}

A metodologia do DCU utilizada durante as oficinas para criar as atividades dos materiais didáticos sempre respeitou ritmo, linguagem, história de vida (o contexto histórico que eles viveram), assim como declínios decorrentes da idade, tais como: redução da memória de curto termo, tempo de resposta e diminuição da psicomotricidade, entre outros.

Essa metodologia permitiu que o aprendiz idoso criasse seu próprio conhecimento a partir de suas iniciativas particulares, além de compartilhar com os outros participantes o seu saber, tornando-o coletivo. Este trabalho apresentou também uma correlação de cada atividade do material didático com os estímulos das inteligências múltiplas e o uso das abordagens ergonômicas durante o processo de desenvolvimento de materiais para idosos, a fim de torná-los mais inteligíveis, acessíveis e com o intuito que, durante sua utilização, possam estimular as inteligências múltiplas dos idosos.

Notou-se que, ao perceber que estava aprendendo com o apoio do material didático desenvolvido, o idoso sentiu-se mais seguro, tornando-se um explorador e, assim, legitimando suas ações no computador e suas ferramentas de informação e comunicação, ajudando-o a desenvolver sua capacidade lógico-formal para cada nível de interação (recursão) alcançado nas atividades com o material didático.

Torna-se também necessário privilegiar questões sobre interação humano-computador, como o envolvimento dos usuários (design centrado no usuário) durante as etapas de desenvolvimento e validação desses materiais, produtos ou projetos. Além disso, deve-se atentar para os itens referentes à acessibilidade e inteligibilidade dos conteúdos, tais como: textos, figuras, condução do usuário entre as tarefas de cada atividade, conteúdos concisos e claros e utilização de uma linguagem de fácil entendimento.

Outra constatação é que o idoso tem interesse e possibilidade de conseguir certa autonomia diante do computador, e o contato com a informática pode propiciar-lhe alguns benefícios, como melhor interação social e estímulo mental. Porém, promover a inclusão do idoso no contexto do mundo digital exige, acima de tudo, levar em conta sua linguagem, sua história de vida, suas alterações cognitivas, emocionais e físicas etc.

Este estudo procurou atender às Leis n. 8.842/1994 e n. 10.741/2003 no que se refere ao desenvolvimento de programas educacionais direcionados para o idoso, oportunizando algumas condições para 
desenvolver material didático adequado aos idosos. Trabalhos com o intuito de aprofundar essa temática com dados quantitativos estão sendo realizados para publicações futuras.

Este trabalho soma-se ao esforço de pesquisa que vem sendo desenvolvido na área de interface humano-computador no sentido de promover a acessibilidade dos idosos à inclusão digital. Importante lembrar que a pessoa idosa é capaz de interagir com o computador e com o meio digital, ampliando seu horizonte de possibilidades e relações; basta que, para isso, acredite-se na sua potencialidade e lhe sejam oferecidos materiais didáticos e estratégias de ensino atrativas, inteligíveis e acessíveis.

\section{REFERÊNCIAS}

Brasil.. Lei 10.741, de $1^{\circ}$ de outubro de 2003.

CAÑAS, José Juan; WAERNS, Yvonne. Ergonomía Cognitiva: Aspectos Psicológicos de la interacción de las personas con la tecnologia de la informacíon. Madrid: Editorial Medica Panamericana, 2001.

ABEELE, V. Vanden; VAN ROMPAEY, V. Introducing human-centered research to game design. Game concepts for and by Senior Citizens. Proceedings of ACM SIG CHI, 2006.

CYBIS, W. de A. Engenharia de usabilidade: uma abordagem ergonômica. Disponível em: <http://www.labiutil. inf.ufsc.br/hiperdocumento/conteudo.html>. Acessoem:o8fev. 2006.

IBGE. Sinopse do Censo Demográfico - 2010. Rio de Janeiro: IBGE, 2011b. Disponível em: http://www.ibge.gov.br/ home/estatistica/populacao/censo2010/default_sinopse.shtm. Acesso em: 04/12/12.

ISO 13407 - Human-centred design processes for interactive systems.

MEDINA, A. R. Ergonomía cognitiva y usabilidad. Disponível em: <http://www.um.es/docencia/agustinr/Tema6-0607a.pdf>. Acessadoem: 17 jul. 2007.

MULLER, M. J. et al. Participatory Practices in the software life cicle. Handbook of Human-computer Interaction, ElsavierSience B.V., 1997.

NETI. Núcleo de Estudos da Terceira Idade da Universidade Federal de Santa Catarina. Disponível em: <http:// www.neti.ufsc.br/>. Acesso em: 22 mar. 2012.

NOGUEIRA, Nilbo R. Pedagogia dos projetos: uma jornada interdisciplinarrumo ao desenvolvimento das múltiplas inteligência. São Paulo: Érica, 2001.

SAYAGO, S. et al. Meeting educational needs of the elderly in ICT: two exploratory case studies. ACM Crossroads, vol 14, n. 2, dec. 2007.

SALES, M. B. Desenvolvimento de um checklist para a avaliação de acessibilidadeda Web para usuários idosos. 2002. Dissertação (Mestrado em Engenharia deProdução) - Universidade Federal de Santa Catarina, Florianópolis, 2002.

. Modelo multiplicador utilizando a aprendizagem por pares focado no idoso. 2007. Tese (Doutorado em Engenharia e Gestão do Conhecimento) - Universidade Federal de Santa Catarina, Florianópolis-SC, 2007 . 
; Fialho, Francisco. A. P., Alvarez, A. M. Guarezi, R. C. Abordagem Pedagógica e Elaboração Material Didático Acessível para o Idoso. Athena.Revista Científica de Educação (Online). , v.8, p.21 - 34, 2007b.

_______.; MARIANI, A. C.; ALVAREZ, A. M. Informática para Terceira Idade. Goiânia: Ed. R\&F editora Ltda, 2007c. .; MARIANI, A. C.; ALVAREZ, A. M. Informática para Terceira Idade. Rio de Janeiro: Ed. Moderna, 2009.

RAABE, André L. A. et al. Promovendo inclusão digital dos idosos através de práticas design participatório. Contrapontos, Revista de Educação da Universidade do Vale do Itajaí, v. 5, n. 3., set./dez. 2005.

THIOLLENT, M. Metodologia da pesquisa-ação. São Paulo: Cortez; 1998.

XAVIER, A. J.; SALES, M. B. Cognition, Interaction and Ageing: an Internet workshops exploratory study, Medical and Care Compunetics in Tecnology and Informatics 103. Bos L, Laxminarayan S, Marsh A.IOS Press, Amsterdam , 2004. 